\title{
The influence of metallostatic pressure, grain refiner, and modification on the critical solid fraction (CSF) of cast $\mathrm{A380}$ alloy
}

\author{
Murat Çolak* And Derya Dispinar** \\ * Bayburt University Engineering Faculty Mechanical Engineering Department Bayburt, TURKEY \\ ** Foseco, R\&D Center, NonFerrous Metal Treatment, Enschede, Netherlands \\ *Corresponding Author : mcolak@bayburt.edu.tr
}

Submitted : 14/06/2019

Revised : 20/02/2020

Accepted :28/11/2020

\begin{abstract}
In this work, porosity formation with regard to the change in the metallostatic pressure was investigated. Different geometry was generated to simulate the effect of pressure on critical solid fraction. A380 alloy was sand cast. Additionally, the effect of grain refiner and modifiers was also investigated. Samples were subjected to X-ray radiography and density measurement to quantify the pore size and distribution.
\end{abstract}

Keywords: A380, Grain refinement, Modification, Feedability, Critical solid fraction.

\section{INTRODUCTION}

Production of defect-free cast aluminum alloys is the ultimate goal in foundries. There are several parameters that affect porosity formation. One of them is the use of optimized size and location of feeders. As the liquid alloy solidifies, the change in the volume due to the density difference between solid and liquid generates a phenomenon called shrinkage. The fundamental aspect of shrinkage is based on the flow of the liquid metal through the mushy zone so-called feedability. When the solid fraction reaches a certain value, the dendritic network no longer allows the flow of the remaining liquid. Thus, shrinkage defects occur. Therefore, several works have been carried out in the literature about the feedability of cast alloys (Han, 2003, Lee 2001, Khalajzadeh 2019, Khajeh 2010). The first systematic measurement of permeability was carried out by Piwonka (1966). Then, Nielsen (2000) was one of the pioneers who studied experimentally the flow of liquid through the mushy zone. The permeability constant in Darcy's Equation was extracted. Since dendritic coherency is the most dominant factor, grain refinement can easily aid the flow of liquid. Additionally, in Al-Si alloys, the modification of Si by Sr is known to depress the eutectic temperature; thus, the feedability can further be enhanced by such modifications, which mainly alters the critical solid fraction. Campbell (2003) had explained the feeding mechanism and reported that a critical solid fraction of 0.65 can be reached for sound castings. Dispinar (2008) had reported that A356 alloy's critical solid fraction can be as high as 0.60. Duncan (1999) showed that coarsening during isothermal holding decreases liquid fracture, which decreased permeability.

Dash (2001) reported that, in sand casting, Sr modification had increased the pore formation. It is important to note that after a critical solid fraction is reached, the remaining liquid is in the composition of the eutectic phase. And 
it is well known that eutectic alloys have the highest fluidity. Therefore, the permeability can be high at such solid fractions. It is also known that $\mathrm{Sr}$ modification decreases eutectic temperature, which should aid the flow of liquid. It is important to note that the liquid metal's cleanliness can easily affect fluidity. Han (2003) had mentioned that oxides and inclusions notably affect permeability. There are studies in the literature that report contradicting results for pore formation in the presence of $\mathrm{Sr}$ in Al-Si alloys. Some claim that $\mathrm{Sr}$ increases porosity Samuel (2017), and some claimed that Sr decreases porosity Samuel (2019). However, Wang (2019) had reported that Sr modification can change the bifilm structure in the melt from $\mathrm{Al}_{2} \mathrm{O}_{3}$ to spinel Sr-oxides, which fractures the oxide into smaller pieces, which increased pore formation. Uludag $(2017,2018)$ had also explained the solidification mechanisms of three different Al-Si alloys and showed that the remaining liquid may contain bifilms, which results in hot tearing. Dash (2001) studied the effect of iron intermetallics on the feedability of Al-Si alloys. It was found that the formation of Fe intermetallics retarded the flow of liquid and resulted in shrinkage porosity. Puncreobutr (2014) used 4D synchrotron X-ray to show that $\beta$-Fe intermetallics reduce the permeability. However, Cao $(2003,2004)$ had shown that $\mathrm{Fe}$ intermetallics were formed in the presence of bifilms, where the wetted side of the oxides had acted as heterogeneous nucleation sites for intermetallics to form. Therefore, the cleanliness of the melt has to be considered when feedability and/or porosity formation are discussed. Hajkowski (2012) claimed that porosity was dependent on cooling rate, and as solidification rate was increased, porosity was decreased. Campbell (2003) and Dispinar (2004, 2010) had shown that the cooling rate only affects the unraveling of bifilms.

In this work, A380 alloy was used, and the effect of grain refiner, modification, and static liquid height on the shrinkage was investigated.

\section{EXPERIMENTAL WORK}

\subsection{Design}

The patterns were created with the aim to produce two different cast parts with different sizes of feeders. An off-set pouring basin, tapered down sprue was used to fill the mould cavity by counter-gravity filling, such that the effect of turbulence was eliminated. The geometry of the feeders was measured to have the same solidification modulus, but with different heights. SolidCast simulation was used for the optimization of the castings. The necks were designed, so that a certain amount of liquid would feed the cast part, and shrinkage would occur. In Figure 1, Model 1 can be seen, where the height of the feeder is 60 with a radius of $60 \mathrm{~mm}$. In Figure 2, Model 2 design is given, where the height of the feeder is 90 with a radius of $45 \mathrm{~mm}$. 

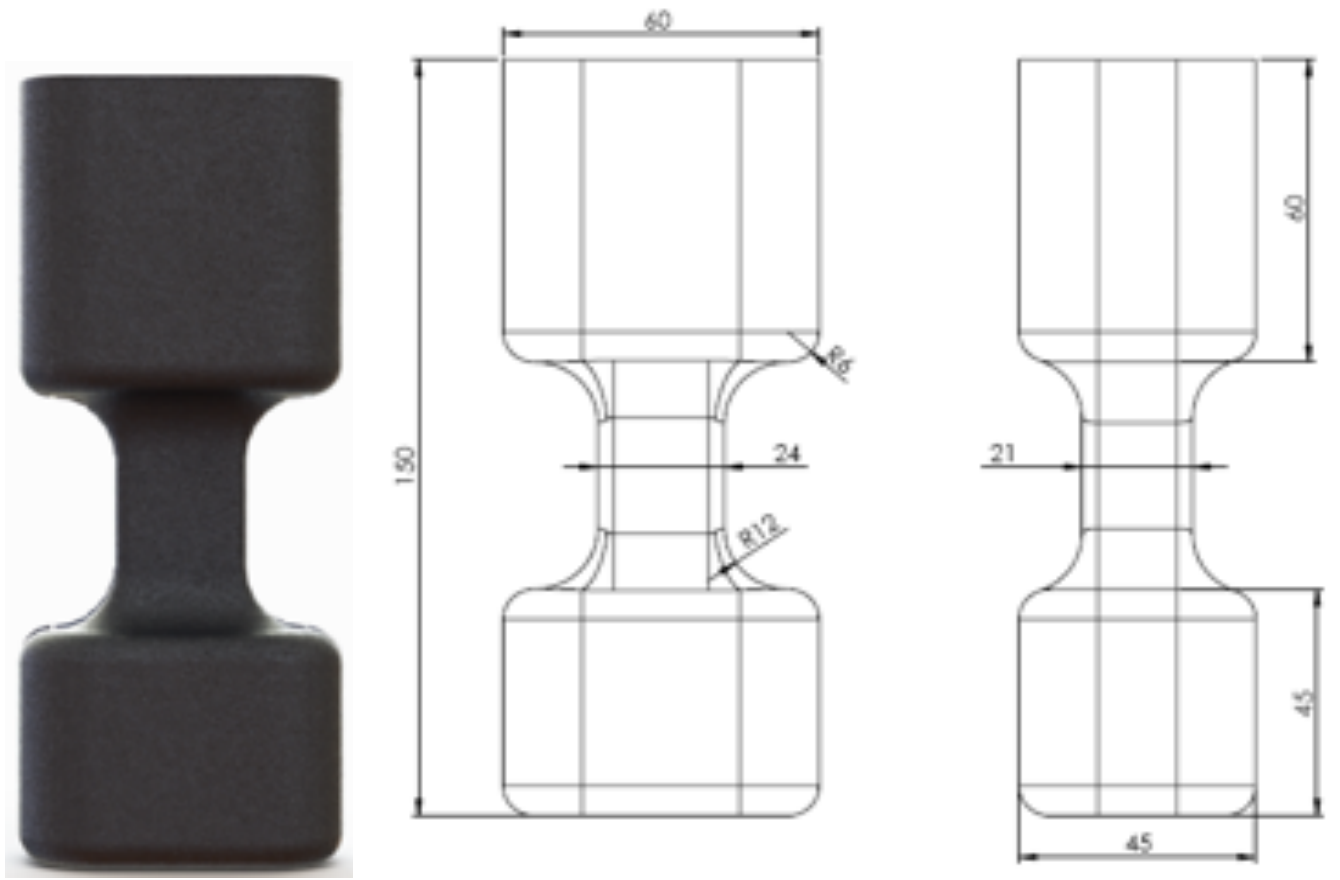

Figure 1. Geometry of Model 1.
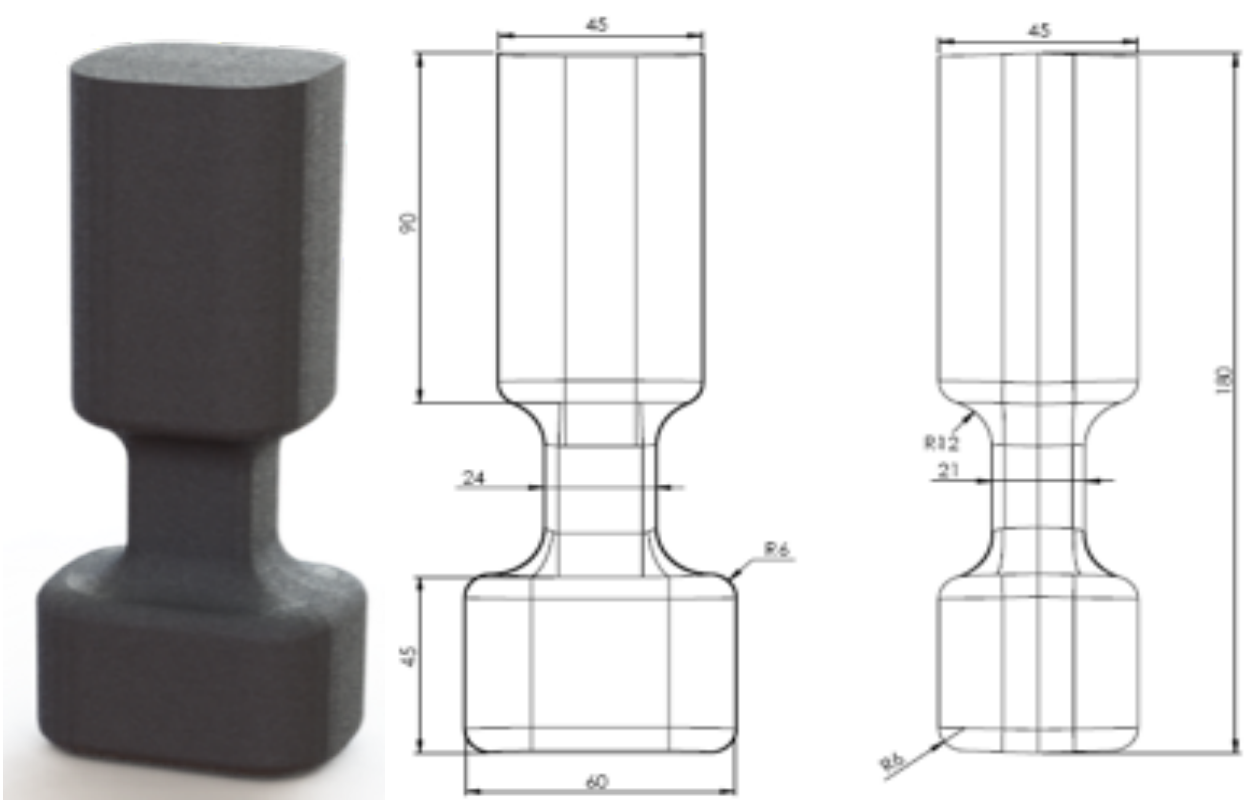

Figure 2. Geometry of Model 2.

After the designs were set, patterns were built as seen in Figure 3. 


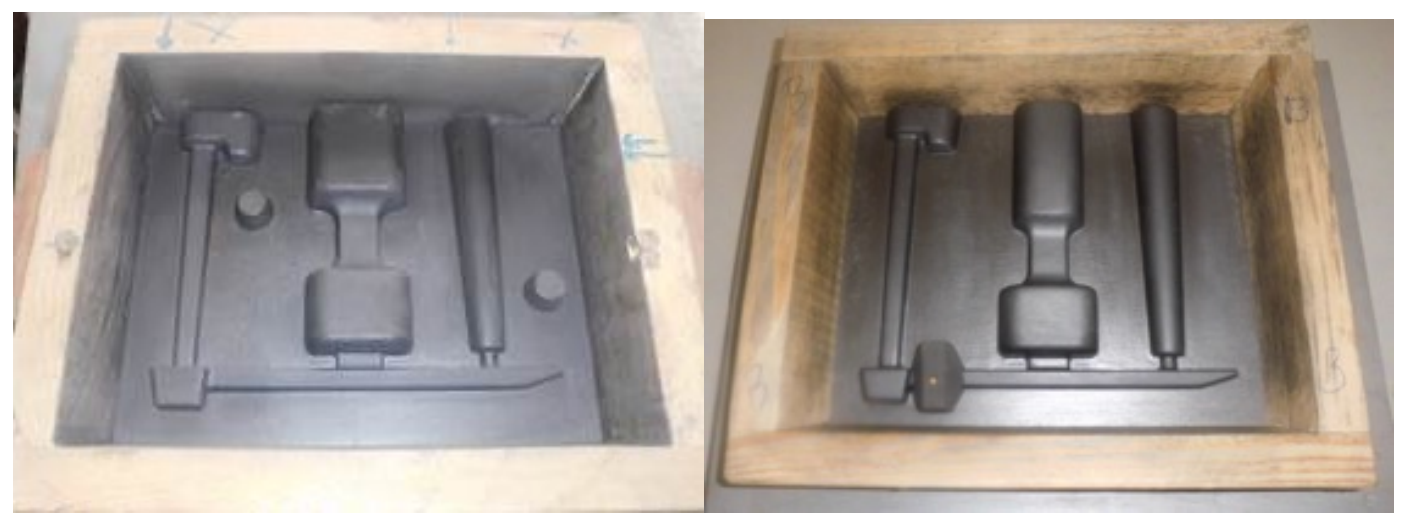

Figure 3. (a-b). Patterns of (a) Model 1 and (b) Model 2.

\subsection{Mould Preparation And Casting Experiments}

The sand moulds were prepared by $\mathrm{CO} 2$ hardened silica sand with a resin ratio of $2.5 \mathrm{wt} \%$. After degassing dross was skimmed, castings were made with the alloy matrix given in Table 1.

Table 1. Sand cast test setup.

\begin{tabular}{|l|l|l|l|l|}
\hline Alloy & Ingot & Filter & Grain refiner & Modifier \\
\hline A380 & Primary & 20 ppi ceramic & no & no \\
\hline A380 & Primary & 20 ppi ceramic & $\% 0,2$ Ti by A15Ti1B & no \\
\hline A380 & Primary & 20 ppi ceramic & $\% 0,2$ Ti by A15Ti1B & $\% 0,2 \mathrm{Sr}$ by Al10Sr \\
\hline
\end{tabular}

Casting alloy studied in this work was A380, where the chemical compositions are given in Table $2.8 \mathrm{~kg}$ capacity resistance furnace was used, and the melting was carried out in $\mathrm{SiC}$ crucible at $690^{\circ} \mathrm{C}$. After the addition of modifier and/or grain refiner, Ar degassing was carried out for 15 minutes. Reduced pressure test samples were collected for measuring the melt cleanliness levels.

Table 2. Chemical analysis of A380 alloy.

\begin{tabular}{|l|l|l|l|l|l|l|l|l|l|l|}
\hline Alloy & Si & Fe & $\mathbf{C u}$ & $\mathbf{M n}$ & $\mathbf{M g}$ & $\mathbf{Z n}$ & $\mathbf{T i}$ & $\mathbf{B}$ & $\mathbf{S r}$ & $\mathbf{A l}$ \\
\hline A380 & 8,480 & 0,248 & 3,370 & 0,112 & 0,198 & 0,013 & 0,011 & 0,001 & 0,004 & Rem. \\
\hline A380-TiB & 8,600 & 0,221 & 3.130 & 0,105 & 0,188 & 0,015 & 0,194 & 0,009 & 0,003 & Rem. \\
\hline A380-TiB+Sr & 8,370 & 0,249 & 3,460 & 0,113 & 0,206 & 0,016 & 0,175 & 0,002 & 0,192 & Rem. \\
\hline
\end{tabular}




\section{EXPERIMENTAL RESULTS}

After the samples were taken out from the moulds, the sand was cleaned, and the surface sink on the top was observed and measured. The radiographic analysis was carried out, and the results are summarized in Figures 4 and 5 for Models 1 and 2, respectively. As can be seen, the images were collected from the front and side views.

\subsection{Radiograph Analysis}

It can be seen from Figures 4 and 5 that, in both Models, the porosity level is higher for the unmodified alloy. For Model 1, when $\mathrm{Ti}$ and/or $\mathrm{Sr}$ is added, there is a centerline porosity starting from the necking area that leads towards the cast piece. On the other hand, in Model 2, these pores were not observed, and more sound cast part was found according to the X-ray results.

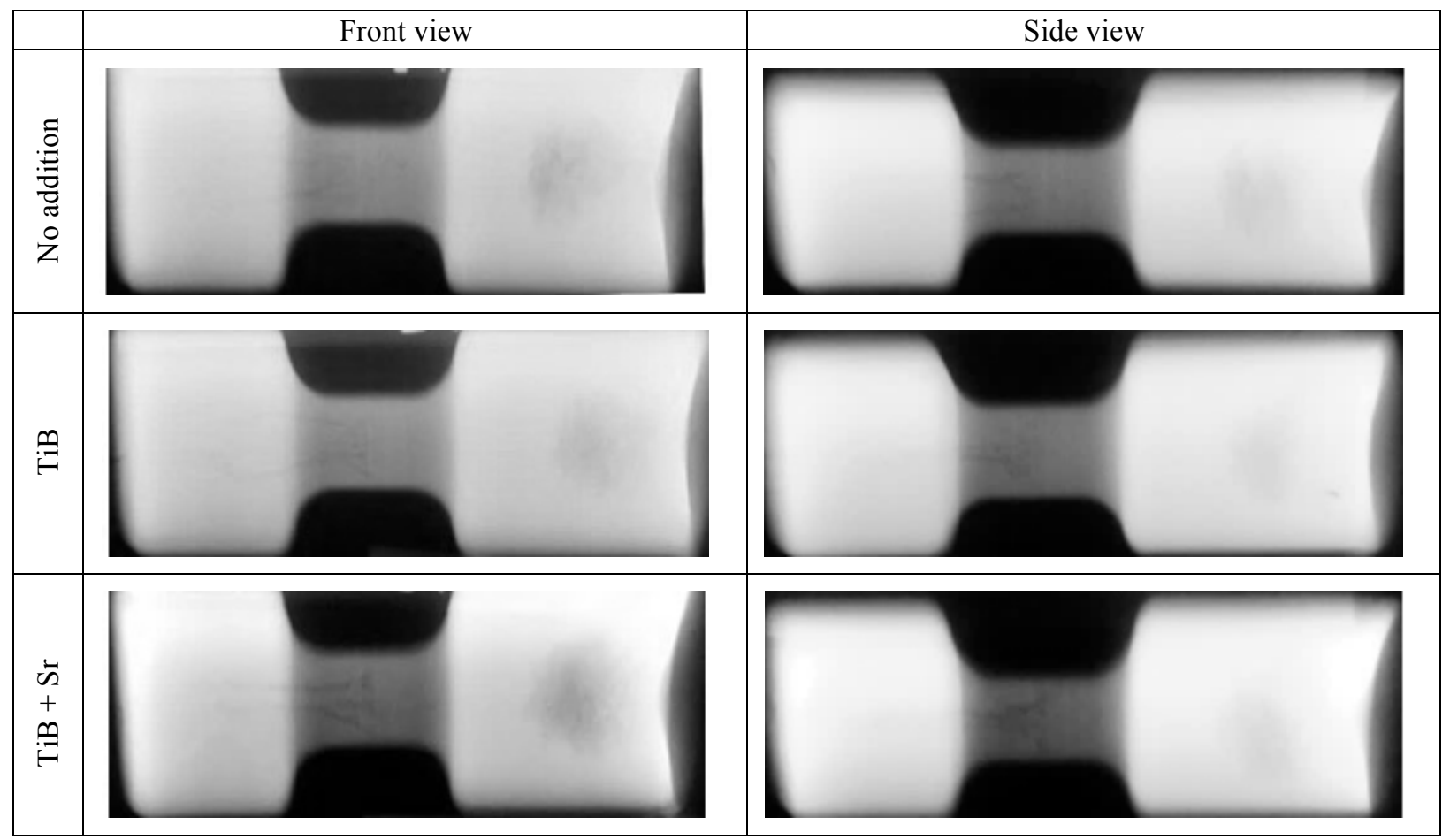

Figure 4. X-ray images of A380 alloy cast in Model 1.

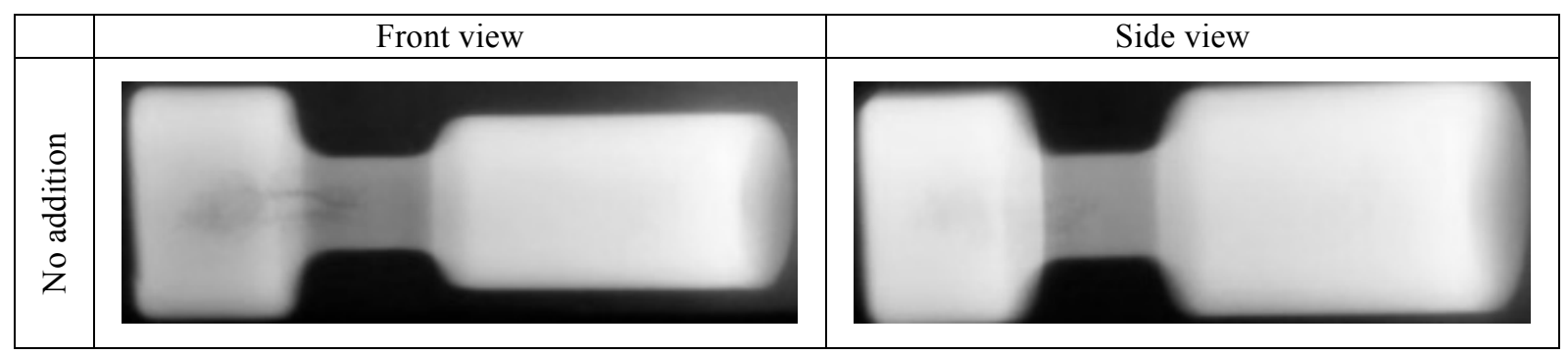




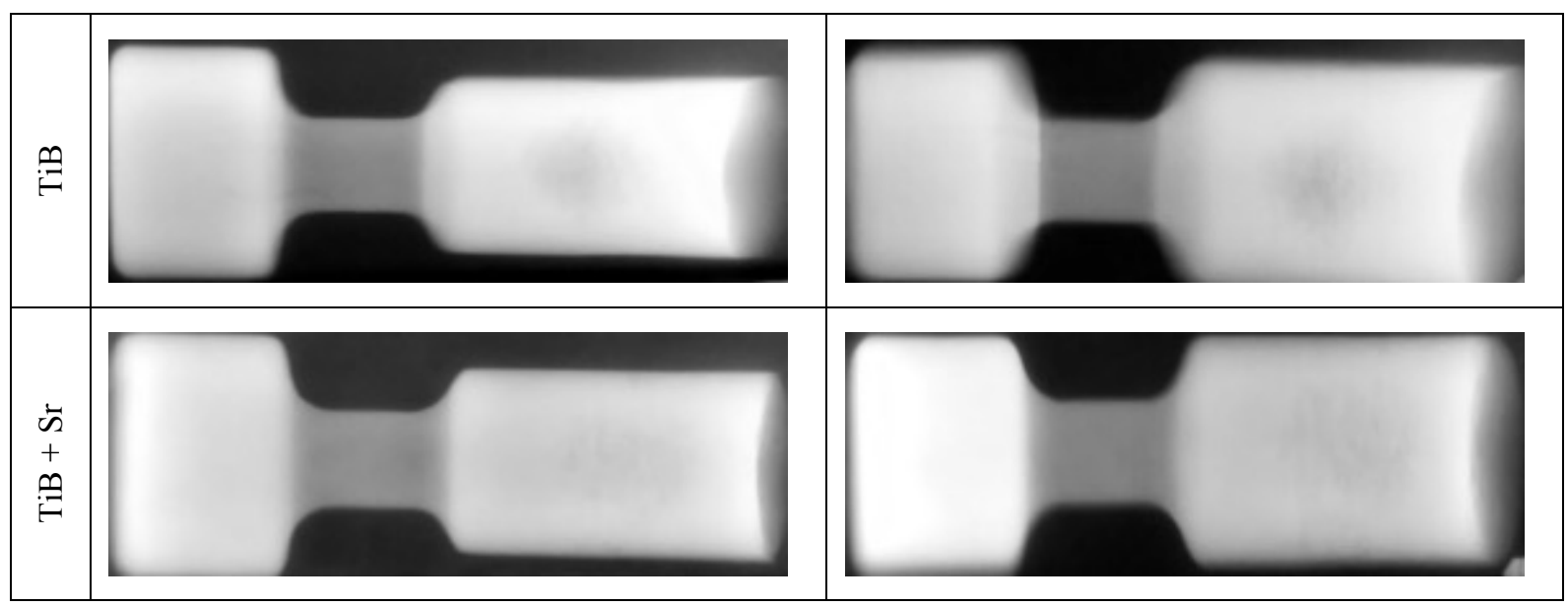

Figure 5. X-ray images of A380 alloy cast in Model 2.

\subsection{Density Measurements}

After the feeders were cut off, the densities of the cast piece with the neck were measured. Archimedes Principle was used; thus, the weight in air and water was measured as seen in the following equation:

$$
\text { volumetric porosity }=\frac{\text { density in the air }}{(\text { density in air }- \text { density in water })} .100
$$

The density measurement results are summarized in Table 3.

Table 3. Volumetric density measurement results.

\begin{tabular}{|c|c|c|c|c|c|}
\hline Sample & $\begin{array}{c}\text { In air } \\
\text { (gr) }\end{array}$ & $\begin{array}{c}\text { In water } \\
\text { (gr) }\end{array}$ & $\begin{array}{c}\begin{array}{c}\text { Experimental } \\
\text { density }\end{array} \\
\left(\mathrm{gr} / \mathrm{cm}^{3}\right)\end{array}$ & $\begin{array}{c}\text { Reference } \\
\text { density } \\
\left(\mathrm{gr} / \mathrm{cm}^{3}\right)\end{array}$ & $\begin{array}{c}\text { Volumetric } \\
\text { porosity } \\
\%\end{array}$ \\
\hline \multicolumn{6}{|l|}{ Model 1} \\
\hline A380 & 347,26 & 216,66 & 2,6542 & 2,7366 & 3,01 \\
\hline A $380+A 15 T i 1 B$ & 346,66 & 217,82 & 2,6858 & 2,7416 & 2,04 \\
\hline $\mathrm{A} 380+\mathrm{A} 15 \mathrm{Ti} 1 \mathrm{~B}+\mathrm{A} 110 \mathrm{Sr}$ & 348,48 & 219,82 & 2,7037 & 2,7402 & 1,33 \\
\hline \multicolumn{6}{|l|}{ Model 2} \\
\hline A380 & 354,98 & 220,74 & 2,6365 & 2,7366 & 3,37 \\
\hline A $380+A 15 T i 1 B$ & 354,52 & 222,04 & 2,6761 & 2,7416 & 2,39 \\
\hline $\mathrm{A} 380+\mathrm{A} 15 \mathrm{Ti} 1 \mathrm{~B}+\mathrm{A} 110 \mathrm{Sr}$ & 351,66 & 221,12 & 2,6938 & 2,7402 & 1,69 \\
\hline
\end{tabular}


A graphical representation of the results given in Table 3 is shown in Figure 6. As can be seen, in both of the Models, the volumetric porosity decreases with Ti grain refinement, and it is further decreased by Sr modification. As the grains become finer, the path for liquid to flow through increases, and thus the feedability increases. Additionally, in the presence of $\mathrm{Sr}$, the $\mathrm{Si}$ is refined, and eutectic temperature decreases, and thereby, the feedability further increases.

When Model 1 and Model 2 are compared, it can be seen in Figure 6 that Model 2 has higher porosity content than Model 1. In both models, the solidification modulus is the same. However, in Model 2, the height is higher with a narrow cross-section. It can be understood that the metallostatic height is less important than the cross-section of the feeder.

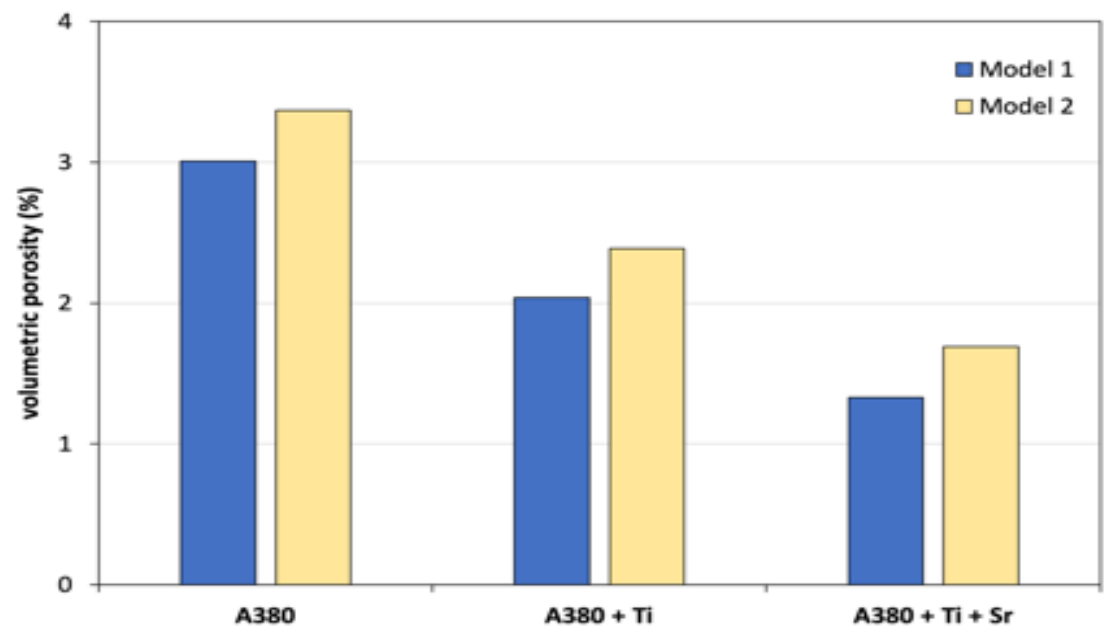

Figure 6. Density measurements and volumetric porosity of A380.

As seen in Figure 6, for the base alloy without any modification, the porosity level is around 3,01\% for Model 1. For the static liquid pressure in Model 2, more porosity was measured with a value of $3.37 \%$. When the alloy was grain refined with $\mathrm{Ti}$, the porosity levels were decreased to 2,04 and 2,39\% for Models 1 and 2, respectively. After Sr modification, porosity was further decreased to 1,33 and $1,69 \%$.

Based on the simulation results (Figure 7), it can be seen that the liquid metal in the feeder cannot find the path to pressurize the cast part, and thereby shrinkage occurs.

\begin{tabular}{|c|c|c|c|}
\hline Model & $\begin{array}{c}\text { Temperature } \\
\text { distribution }\end{array}$ & $\begin{array}{c}\text { Solidification } \\
\text { time }\end{array}$ & Critical Solid fraction \\
\hline & & &
\end{tabular}




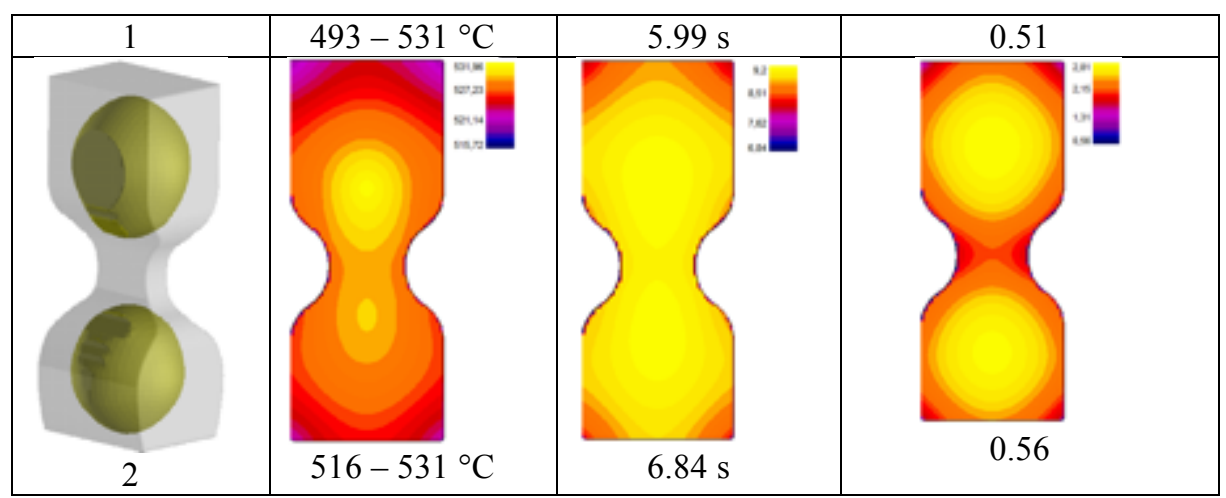

Figure 7. Simulation results for both Models.

Reduced pressure test samples were collected prior to casting the samples. The cross-section of RPT samples and the bifilm index results are given in Figures 8 and 9, respectively.

\begin{tabular}{|c|c|c|}
\hline A380 & Model 1 & Model 2 \\
\hline No addition & & \\
\hline TiB & & \\
\hline TiB $+\mathrm{Sr}$ & & \\
\hline
\end{tabular}

Figure. 8. Cross-section of RPT samples. 


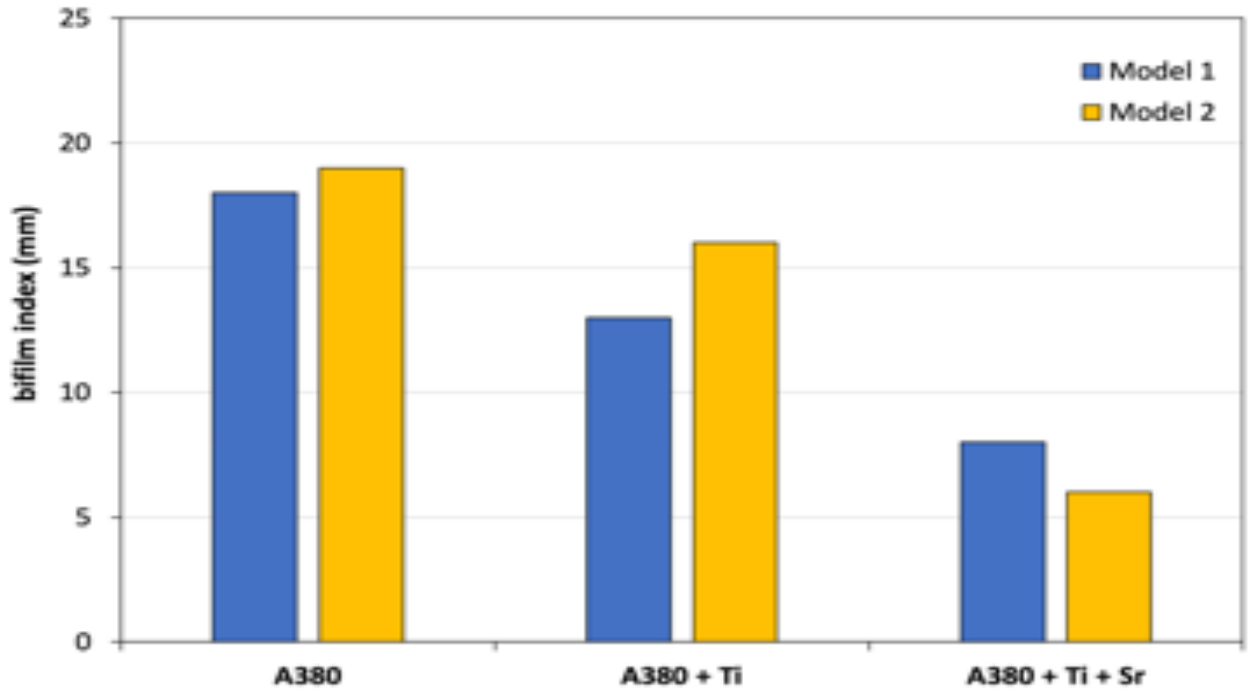

Figure 9. Bifilm index results of castings.

The correlation between bifilm index and volumetric porosity of cast samples is given in Figure 10. Dispinar ${ }^{21}$ had shown that bifilms lead to pore formation. In this work, similar findings were found.

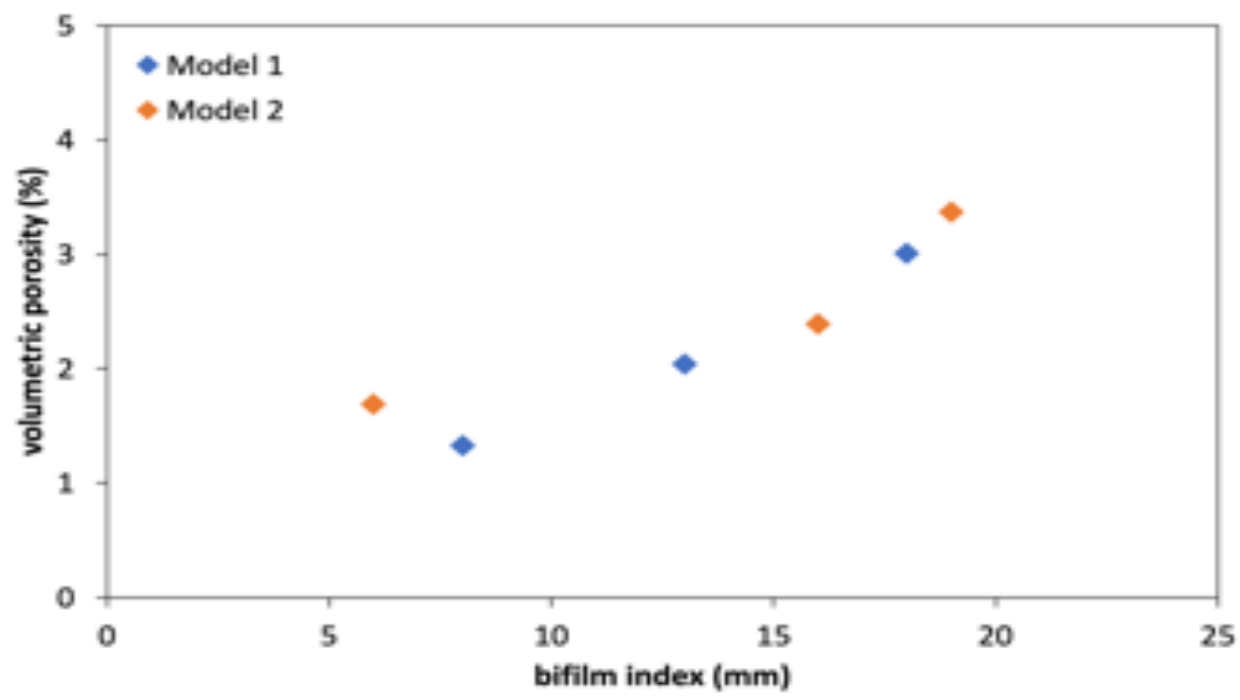

Figure 10. Change of porosity with bifilm index.

\subsection{Cross-section of Cast Parts}

The cast parts were cut from the feeder, and the cross-section was examined for pore size and distribution. The results for Models 1 and 2 are given in Figures 11 and 12. 


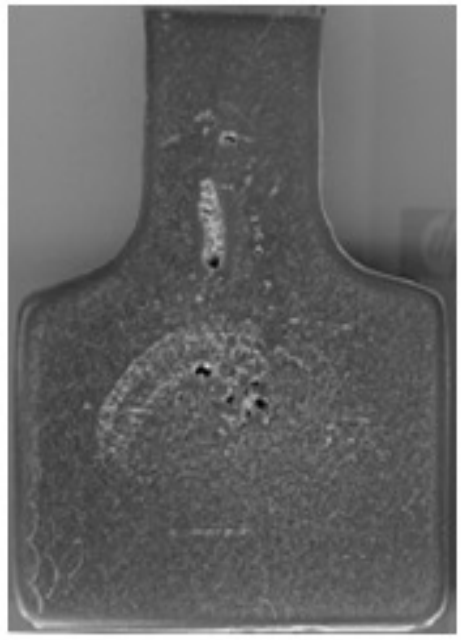

as-received

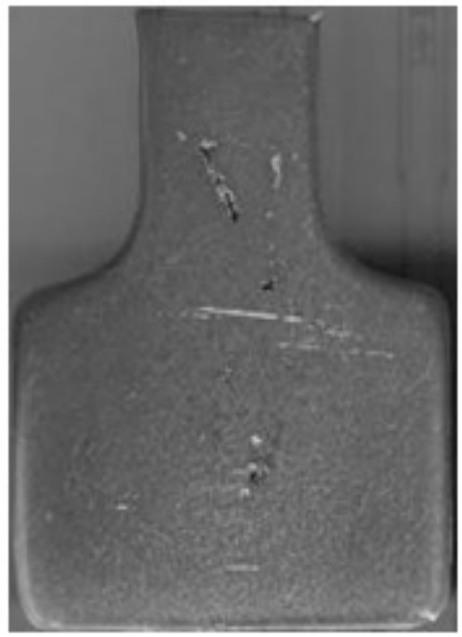

Ti grain refined

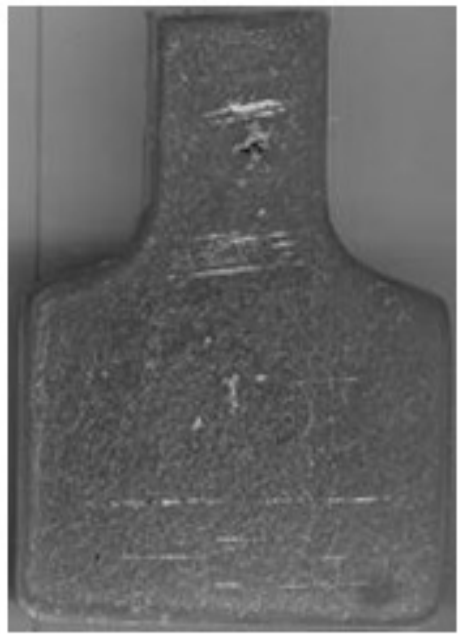

$\mathrm{Ti}+$ Sr modified

Figure 11. Cross-section of Model 1 castings.

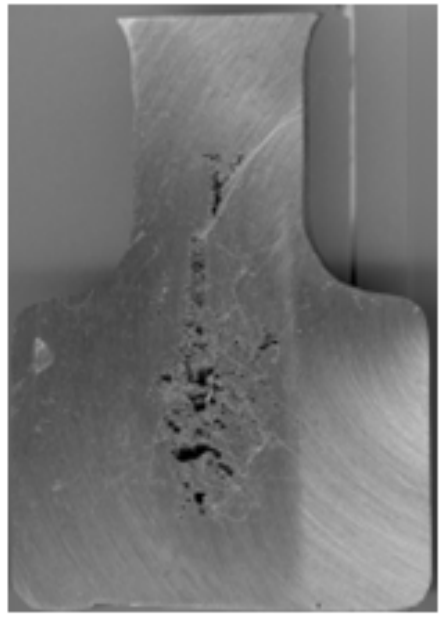

as-received

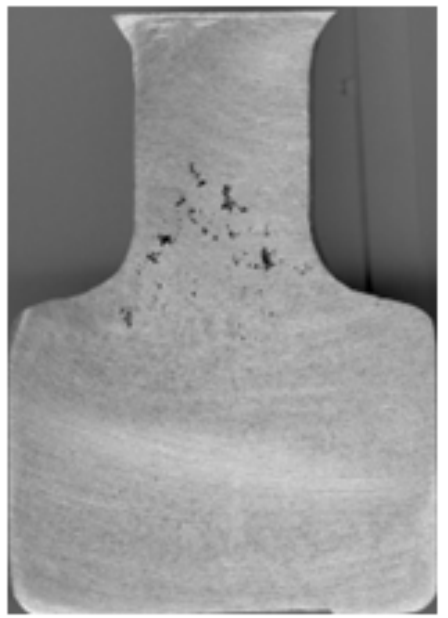

Ti grain refined

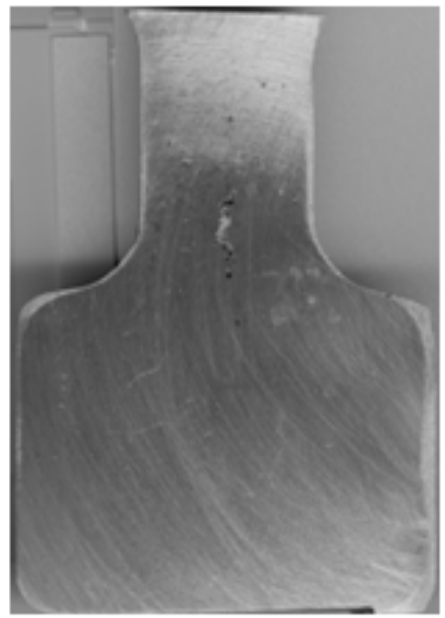

$\mathrm{Ti}+\mathrm{Sr}$ modified

Figure 12. Cross-section of Model 2 castings.

As can be seen in Figure 11, in the as-received and unmodified A380, porosity is located in the center of the cast part. When the alloy is grain refined, the pore size decreases but is almost at the same region. For Sr modified A380, the porosity in the center disappears, and it is located at the neck area. The same scenario applies for castings with Model 2 as seen in Figure 12. However, the total amount of porosity is higher for this design.

During solidification, as dendrites grow, the channel between the mushy zones decreased, and the tortuous path increases, which retards the flow of the liquid. As the restrictions increase, the pressure head required to maintain flow also increases. Therefore, Model 2 was designed to overcome this constraint. However, based on the dimension studied in this work, this effect was not observed. Han 2013 looked into the effect of height of liquid on the 
permeability of $\mathrm{Al}$ alloys. It was reported that oxide and inclusion had the potential to block the flow of the liquid through the dendritic channels.

\section{CONCLUSION}

The effect of critical solid fraction and static liquid metallostatic pressure on the porosity formation of A380 alloy was investigated. Two different patterns were used, and the alloy was grain refined and modified. The findings of this work are summarized as follows:

- Porosity level was measured by density according to Archimedes Principle, metallographic examination, and X-ray radiography. It was found that feedability was low in both designs, which resulted in shrinkage porosity.

- Unmodified as-received alloy revealed the highest porosity level. The lowest porosity was obtained with $\mathrm{Ti}$ grain refinement and Sr modification of A380 alloy. Thus, the critical solid fraction was enhanced, and feedability was increased with such modifications.

- The effect of static liquid height (i.e., metallostatic pressure) was not found to be an effective way to eliminate porosity. The higher height of the feeder had resulted in an increased hot spot in the cast part instead of a higher velocity or better feed path.

- Even if there is enough liquid in the feeder, the geometry of the feeder plays a significant role independent of the solidification modulus.

- There is a direct correlation between bifilm index and volumetric porosity in A380 alloy.

\section{REFERENCES}

Campbell, J. (2003). Castings. In Castings. https://doi.org/10.1016/B978-0-7506-4790-8.X5016-5

Cao, X., \& Campbell, J. (2003). The nucleation of Fe-rich phases on oxide films in Al-11.5Si-0.4Mg cast alloys. Metallurgical and Materials Transactions A: Physical Metallurgy and Materials Science. https://doi.org/10.1007/s11661-003-0253-3

Cao, X., \& Campbell, J. (2004). The solidification characteristics of Fe-rich intermetallics in Al-11.5Si-0.4Mg cast alloys. Metallurgical and Materials Transactions A: Physical Metallurgy and Materials Science. https://doi.org/10.1007/s11661-004-0251-0

Dash, M., \& Makhlouf, M. (2001). Effect of key alloying elements on the feeding characteristics of aluminumsilicon casting alloys. Journal of Light Metals, 1(4), 251-265.

Dispinar D., Ellingsen K., Di Sabatino M., A. L. (2008). Measurement of permeability of A356 aluminium alloys. 2nd Int. Conf. Advances in Solidification Processes, 1-6. Graz.

Dispinar, D., Akhtar, S., Nordmark, A., Di Sabatino, M., \& Arnberg, L. (2010). Degassing, hydrogen and porosity phenomena in A356. Materials Science and Engineering: A, 527(16-17), 3719-3725.

Dispinar, D., \& Campbell, J. (2004). Critical assessment of reduced pressure test. Part 1: Porosity phenomena. International Journal of Cast Metals Research, 17(5), 280-286.

Duncan, A. J., Han, Q., \& Viswanathan, S. (1999). Measurement of liquid permeability in the mushy zones of aluminum-copper alloys. Metallurgical and Materials Transactions B, 30(4), 745-750.

Hajkowski, M., \& Hajkowski, J. (2012). Mechanical properties of Al-Si-Mg alloy castings as a function of structure refinement and porosity fraction. Archives of Foundry Engineering, 12(4), 57-64. 
Han, Q., Viswanathan, S., \& Duncan, A. J. (2003). Permeability measurements of the flow of interdendritic liquid in equiaxed aluminum-silicon alloys. Metallurgical and Materials Transactions B, 34(1), 25-28.

Khajeh, E., \& Maijer, D. M. (2010). Physical and numerical characterization of the near-eutectic permeability of aluminum-copper alloys. Acta Materialia, 58(19), 6334-6344.

Khalajzadeh, V., Goettsch, D. D., \& Beckermann, C. (2019). Real-time X-ray Radiography and Computational Modeling of Shrinkage Porosity Formation in Aluminum Alloy Castings. Metallurgical and Materials Transactions A, 50(2), 757-771.

Lee, P. D., Chirazi, A., \& See, D. (2001). Modeling microporosity in aluminum-silicon alloys: a review. Journal of Light Metals, 1(1), 15-30.

Nielsen, Ø., \& Arnberg, L. (2000). Experimental difficulties associated with permeability measurements in aluminum alloys. Metallurgical and Materials Transactions A, 31(12), 3149-3153.

Piwonka, T. S., \& Flemings, M. C. (1966). Pore formation in solidification. Aime Met Soc Trans, 236(8), 11571165.

Puncreobutr, C., Phillion, A. B., Fife, J. L., \& Lee, P. D. (2014). Coupling in situ synchrotron X-ray tomographic microscopy and numerical simulation to quantify the influence of intermetallic formation on permeability in aluminium-silicon-copper alloys. Acta Materialia, 64, 316-325.

Samuel, A. M., Doty, H. W., Valtierra, S., \& Samuel, F. H. (2017). Porosity formation in Al-Si sand mold castings. International Journal of Metalcasting, 11(4), 812-822.

Uludağ, M., Çetin, R., Dispinar, D., \& Tiryakioğlu, M. (2017). Characterization of the Effect of Melt Treatments on Melt Quality in Al-7wt \%Si-Mg Alloys. Metals. https://doi.org/10.3390/met7050157

Uludağ, M., Çetin, R., Dispinar, D., \& Tiryakioğlu, M. (2018). The effects of degassing, grain refinement \& Sr-addition on melt quality-hot tear sensitivity relationships in cast A380 aluminum alloy. Engineering Failure Analysis. https://doi.org/10.1016/j.engfailanal.2018.03.025

Uludağ, M., Çetin, R., Dişpinar, D., \& Tiryakioğlu, M. (2018). On the Interpretation of Melt Quality Assessment of A356 Aluminum Alloy by the Reduced Pressure Test: The Bifilm Index and Its Physical Meaning. International Journal of Metalcasting. https://doi.org/10.1007/s40962-018-0217-4

Wang, Q., Hao, Q., \& Yu, W. (2019). Effect of Strontium Modification on Porosity Formation in A356 Alloy. International Journal of Metalcasting. https://doi.org/10.1007/s40962-018-00300-1 